\title{
The Autonomous Image Analyzer* - enumeration, measurement and identification of marine phytoplankton
}

\author{
Gabriel Gorsky ${ }^{1}$, Pierre Guilbert ${ }^{1}$, Eva Valenta ${ }^{2}$ \\ ${ }^{1}$ Station Zoologique, F-06230 Villefranche-sur-mer, France \\ ${ }^{2}$ Rheinisch-Westfälische Technische Hochschule, D-5100 Aachen, Federal Republic of Germany
}

\begin{abstract}
An inexpensive, automated system is described for counting, measuring and identifying objects in an aqueous suspension. The results of counting and measurement obtained from the image analyzer were compared to results from visual analysis and a sensor analyzer (HIAC/ROYCO). For a mixture of 3 algal species, each having a characteristic size and shape (Prorocentrum micans, Nitzchia closterium and Hymenomonas elongata), the sensor analyzer failed to distinguish among the 3 species, while results obtained by the image analyzer and with visual methods did not differ significantly; the analyzer identified and counted each of them accurately. If the resolution of the input image is adequate, the image analyzer can identify and classify up to 26 different forms in one sample. The operator need not be present while the samples (up to 40) are being processed. The discussion considers the extension of the method for the counting and sizing of objects with relatively complex geometries like copepods and other zooplankton.
\end{abstract}

\section{INTRODUCTION}

Unicellular marine algae can be counted and identified visually using a microscope. Alternatively, particle counts and size distributions can be determined either by the Coulter Counter (Sheldon \& Parsons 1976), which measures changes in an electrical field proportional to particle volume in the sample, or by the HIAC/ROYCO (Pough 1976) light blockage analyzer (suspended particles flowing past a light source partially shade a photodiode, the output of which is converted into equivalent spherical diameters). Microscopic observations are time consuming and laborious, particularly when sample numbers are large, while the automated particles counters do not allow identification of the analyzed particles.

Pattern recognition by image analysis, although common in medicine and industry, has been comparatively little used for studies in marine biology. To date, the image analysis systems used for marine organisms can

\footnotetext{
- The Autonomous Image Analyzer is available from Ysebaert SA., 49, rue Ernest-Renan, F-95320 Saint-Leu-LaForet, France
}

be divided broadly into custom built systems and commercially available systems. The first category comprises the following sophisticated systems: Jeffries et al. $(1980,1984)$ used an Eclipse S/140 with 6 satellites and a Colorado Video frame grabber to identify kinds of zooplankton by discriminant analysis of such parameters as length, width, perimeter and area; their procedures could identify the 8 taxonomic groups with $89 \%$ accuracy at a speed of about 35 organisms min $^{-1}$. Tsuji \& Nishikawa (1984), starting with digitized fluorescence photographs of phytoplankton, could analyze about 70 cells $\mathrm{min}^{-1}$ to determine the standing stock of Prorocentrum triestium during a red tide; the digitizing was achieved with a scanner and the calculations of the Fourier descriptors by a minicomputer which controlled the graphic display. Ferson et al. (1985) used minicomputers to distinguish between 2 populations of the mussel Mytilus edulis on the basis of shape variations of digitized shells. Chehdi \& Boucher (1986) developed algorithms locating, on the image of a crustacean, points characterizing the individual.

The second category comprises the following commercially available image processing systems: Dietrich \& Uhlig (1984) interfaced the 'Quantimet 23 C' system 
to a Digital PDP 11/23 computer, first to measure area, length, width and the length-width ratio of Artemia salina for biomass determination, and, second, to classify and count different stages of the mass cultured copepod Tisbe holothuriae; undesirable items were rejected manually with a light pen. Rolke \& Lenz (1984) studied the size distribution in zooplankton samples with a Quantimet 720 connected to an HP 9825 computer. Furuya (1982) used a Luzex 500 image-processor system for measuring the length and width of 4 species of phytoplankton at a rate of 25 cells min ${ }^{-1}$. Asano \& Tanaka (1984) measured fish eggs with the same equipment. Bjørnsen (1986) estimated the biomass of bacterioplankton in batch cultures using an IBAS, Zeiss/Kontron image analysis system. The processing speed was about 25 cells min ${ }^{-1}$. Sieracki et al. (1985) counted marine bacteria with an image analysis system consisting of an Artek 810 image analyzer and an Olympus BHT-F epifluorescent microscope and reduced the time required for counting manually by $85 \%$. Estep et al. (1986) interfaced a MacIntosh computer to a Artek $810 \mathrm{~V}$ image analysis computer to determine the abundance, size, shape, volume and surface area of organisms ranging from marine bacteria to fish larvae.

One disadvantage of sophisticated methods when compared to the commercially available processors is the difficulty of reproducing the materials and the methods in other laboratories. However, the major inconvenience of both approaches is the necessity of the continuous presence of the operator during the entire analysis. In spite of the increasing dependence on image analysis for identification and sizing of marine organisms, this technique is still in its developmental stage and has by no means yet become a standard laboratory procedure for marine biology.

The purpose of this paper is to describe an inexpensive and autonomous system for image analysis designed as an independent unit, which samples, measures, identifies and prints out the results of series of 40 samples without the continuous presence of the operator. This method is suitable for objects with simple geometric shapes such as the unicellular algae and can be used in conjunction with any microscope.

\section{METHODS}

Sample preparation and analysis. Four species of algae - the haptophytes Isochrysis galbana and $\mathrm{Hy}$ menomonas elongata, the bacillariophycean Nitzchia closterium and the dinophycean Prorocentrum micans - were cultured under continuous light (0.05 ly min ${ }^{-1}$ ) at $17^{\circ} \mathrm{C}$ in $\mathrm{f} / 2$ medium (Guillard 1975). I. galbana was concentrated on a 1 um Nuclepore filter and resuspended in about $1 / 25$ the original volume of seawater After filtration through a $30 \mu \mathrm{m}$ Nytrel net, one part of the algal solution was fixed in a specific fixing solution (see below), the second diluted to a concentration of about $10^{4}$ cells $\mathrm{ml}^{-1}$ and analyzed in the HIAC/ROYCO particle analyzer (Pacific Scientific Inc.) with a $\mathrm{CMH}$ high concentration sensor (60 $\mu \mathrm{m}$ orifice). The fixed part of the sample was immediately counted and measured in a Malassez hemocytometer as well as analyzed by our autonomous image analyzer. The other 3 algae were mixed together $(30 \mathrm{ml}$ of each algal culture before
Fig. 1 The set-up. (1) automated sampler, (2) cantera and optics, (3) computer monitors and keyboard

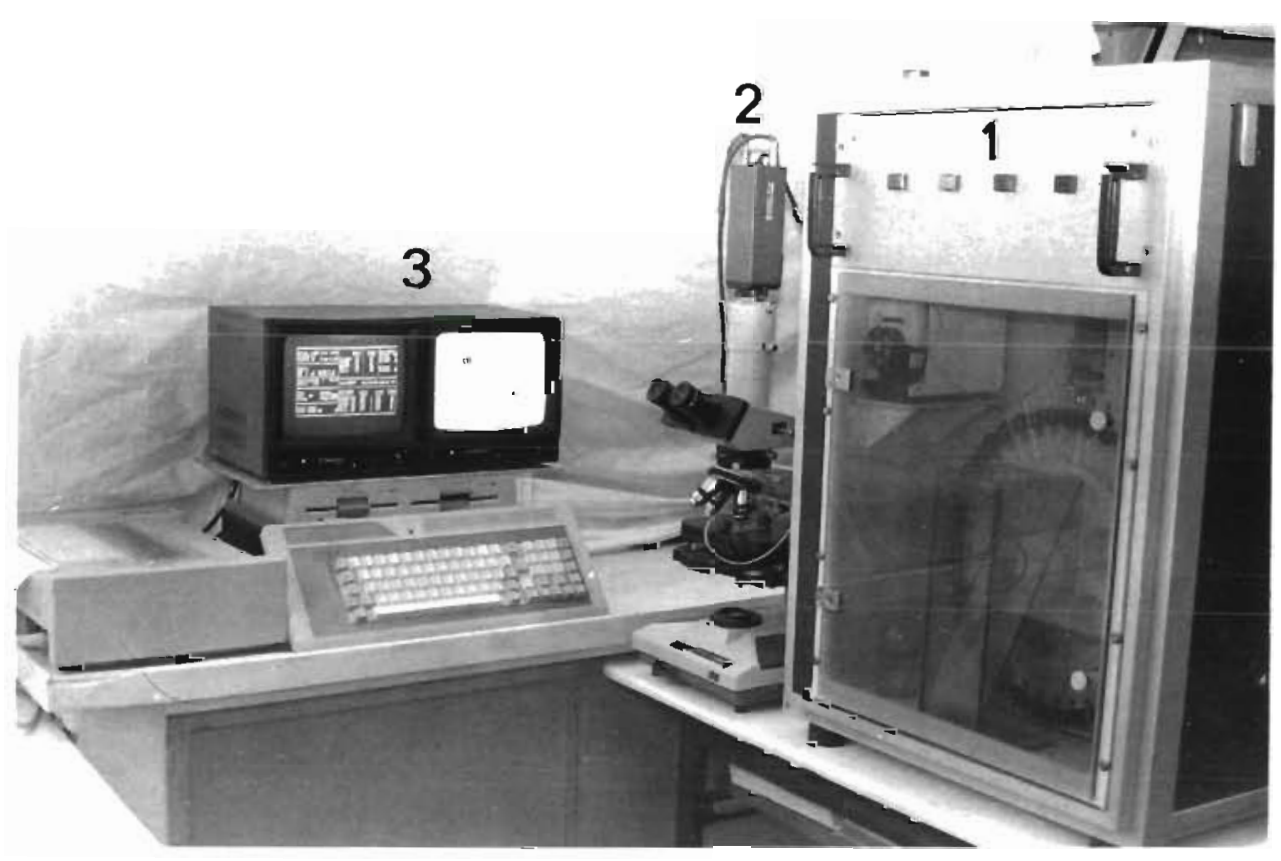


each run) without preliminary counting or concentration. Parallel analysis by the 3 methods followed the protocol described for I. galbana. One of the main difficulties in use of permanent observation devices is particle adherence to the glass surfaces. Chapeau \& Gagnon (1987) provide a review of the effectiveness of several glass coating agents, but this method did not give us entire satisfaction. In order to eliminate the adherence of algal cells to the glass surfaces of the flow chamber, we developed a fixing solution having the desired effect. The composition of this solution will be published elsewhere. We did not observe any change of the shape of algae after fixation. The stirring in the sampler did not damage the algae, and there was no significant difference between the results obtained on fixed or living algae.

System description (Fig. 1). The system described in this paper consists of (1) image acquisition, (2) sampling and (3) computer processing. A monochrome Hitachi KP 141 CCD video camera records the images from a custom-built flow chamber fixed on the stage of an Olympus BH-2 microscope. As in the case of conventional counting chambers, the microscope slide and the cover slip of the flow chamber are separated by spacers 100 or $200 \mu \mathrm{m}$ thick, running the length of the slide and resulting in a flow-through canal measuring
$55 \times 5 \times 0.2 \mathrm{~mm}$ (or $0.1 \mathrm{~mm}$ ). Each spacer contains in addition a groove running the length of the slide which serves as an overflow channel, ensuring a constant volume in the flow chamber. The flow chamber is filled by capillary action. A closed chamber is difficult to keep clean from adhering organic particles. After the analysis the sample is moved to the waste products jar by a multichannel peristaltic pump situated in the automated sampler. The automatic process consists of: (a) the sample, stirred by a vertical rotor, containing up to forty $5 \mathrm{ml}$ tubes with parafilm stoppers; (b) sample transfer into the flow chamber - a syringe moving vertically pierces the stopper and a peristalting pump removes the pre-programmed volume of sample to the counting chamber; (c) the ejection of the sample tube after analysis into a repository. The microscope stage is motorized and the number of fields to be explored can be programmed as well as all the features (Table 1) of the sampler before the execution (for example, time of stirring, volume of transferred sample to the flow chamber, ejection or retention of sample tube in the sampler for repeated counting, and number of fields analyzed can be programmed before or modified during the analysis itself). Interruption of the program is possible at any moment without loss of information. The sampler can work in automatic or manual mode

Table 1. Summary of the functions available by predefined keys ('live' keys) and the settings included in the menu (Fig. 3). Execution of the automatic sequence carries out the complete operation and prints out the results

\begin{tabular}{|c|c|c|}
\hline 'Live' keys & Options & Menu configuration \\
\hline $\begin{array}{l}\text { TEXT/GRAPH } \\
\text { PRINT SCREEN }\end{array}$ & $\begin{array}{l}\text { FILES } \\
\text { - deleting } \\
\text { Calibrate pixel } \\
\text { Units }(\mu \mathrm{m} / \mathrm{mm})\end{array}$ & $\begin{array}{l}\text { Optics (magnification) } \\
\text { Window size }(1-191,1-278)\end{array}$ \\
\hline $\begin{array}{l}\text { CLEAR P1 } \\
\mathrm{P} 1 \longrightarrow \mathrm{P} 2 \\
\mathrm{P} 2 \longleftrightarrow \longrightarrow \mathrm{P} 1\end{array}$ & $\begin{array}{l}\text { MODELS } \\
\text { - list values } \\
\text { - delete one }\end{array}$ & $\begin{array}{l}\text { Thresholding }(0-255) \\
\text { Select filters } \\
\text { Print screen format }\end{array}$ \\
\hline $\begin{array}{l}\text { NOT P1 } \\
\text { P1 AND P2 } \\
\text { P1 ORA P2 } \\
\text { P1 EOR P2 } \\
\text { SMOOTHING } \\
\text { DILATION } \\
\text { EROSION }\end{array}$ & $\begin{array}{l}\text { RESULTS } \\
\text { - compute \& output } \\
\text { - print histogram } \\
\text { - list objects values } \\
\text { ROBOT } \\
\text { - manual mode }\end{array}$ & $\begin{array}{l}\text { ANALYSIS } \\
\text { Bordering objects }(\mathrm{Y} / \mathrm{N}) \\
\text { Parameters } \\
\text { - calculate } \\
\text { - classify } \\
\text { - length (min \& max) } \\
\text { Classification } \\
\text { - select models } \\
\text { - select parameters } \\
\text { - rejection limit }\end{array}$ \\
\hline $\begin{array}{l}\text { INPUT IMAGE } \\
\text { APPLY FILTERS }\end{array}$ & EXECUTE automatic run & $\begin{array}{l}\text { CONFIG. filename } \\
\text { OBJECTS filename } \\
\text { RESULTS } \\
\text { - table of means + SD } \\
\text { - histograms of parameters } \\
\text { - list of objects values } \\
\text { SET UP ROBOT }\end{array}$ \\
\hline
\end{tabular}



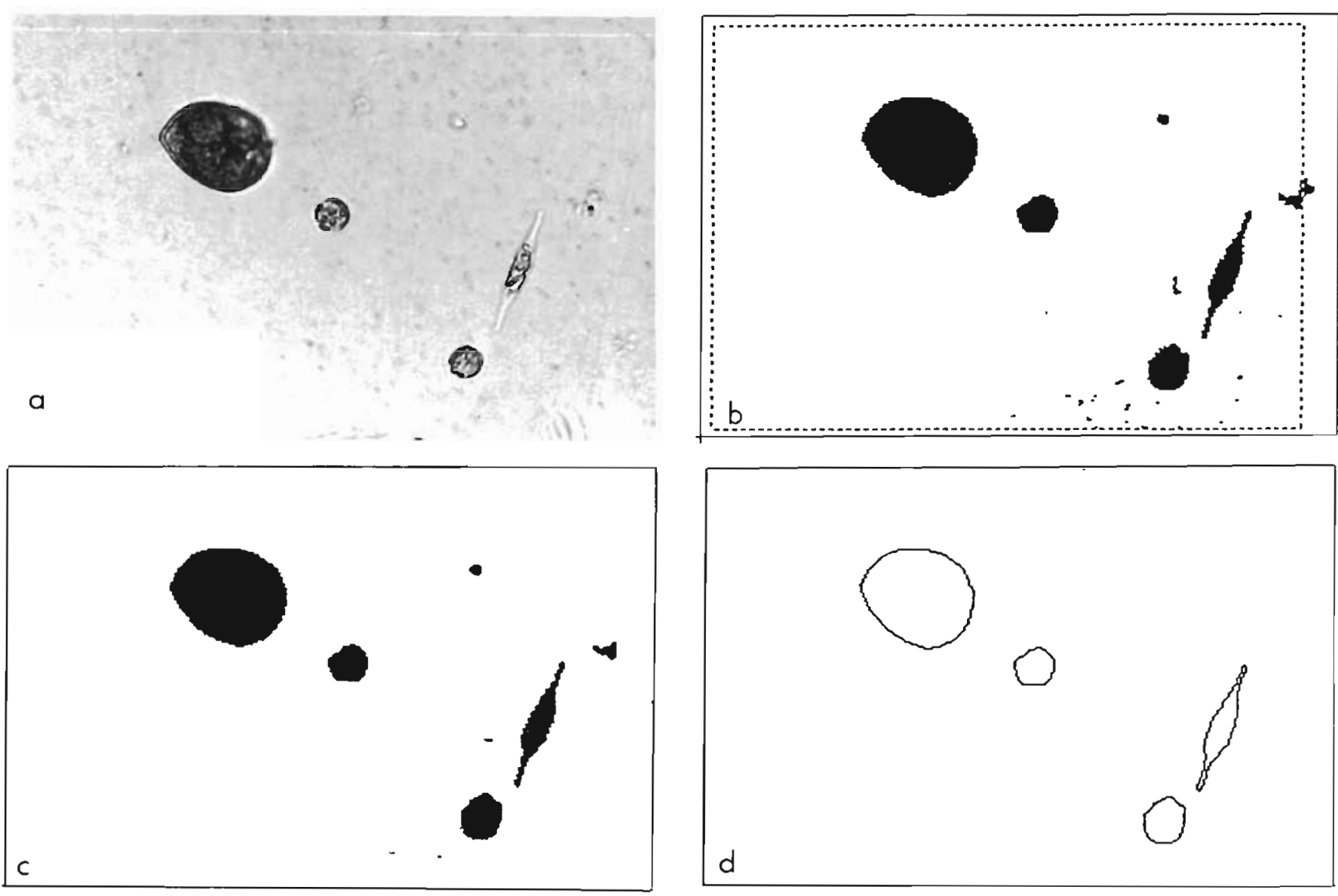

Fig. 2. (a) Light micrograph of the source image. (b) Computer display of the digitalized source image with the window delimiting the area of interest (AOI). (c) Computer display of the digitalized source image after applying a smoothing filter (a binary morphological $3 \times 3$ filter). (d) Computer display of accepted particles

and the transition can be made at any time. The time needed for the sedimentation can be programmed and will be executed after the transfer of the sample to the flow chamber

Calibration of the system. The Image Analyzer was calibrated with a Leitz stage micrometer (10 $\mu \mathrm{m}$ smallest division) for each optical combination used. The known distance in $u m$ was divided by the number of pixels for each combination. The scale factor was linear and was squared to obtain the area square factor which reached $0.34 \mathrm{um}^{2}$ per pixel for the magnification of $165.5 \times$ used for enumerating $I$. galbana. The screenarea is $278 \times 190$ pixels. The video signal (Fig 2a) is digitized by the Dithertizer card (Computer Stations Inc.) and the binary image (Fig. 2b) processed. The software is conceived for rectangular pixels. Calibration showed that deviation from the $1: 1$ ratio is negligible.

System characteristics. After the computer is turned on, the autostart routine displays the entire set-up menu (configuration) on the screen (Fig. 3). Instructions appropriate for the experiment are then entered (this need be done only once for a given type of analysis). Subsequently, a cursor can be moved across the screen, in order to introduce or to modify parameters (i.e. the operator can modify the Area Of Interest 'AOI'; Fig. 2b on the screen and avoid badly illuminated areas. One can decide what parameters to measure, what optical combination to use, improve the image and program the sampler). In order to define models, configuration and object files, and work out the training set, one uses an arrow to point out particies belonging to different models. For the simple shaped objects used in the present study, a training set of 50 objects per model was sufficient. A maximum of 26 models can be defined by the operator. The set up and results can be saved and completed or a new set of analyses done in the same conditions.

A typical sequence of monitor displays is shown in Fig. 2. The input image (Fig. 2a) is transferred to the computer, which displays the raw digitized image with the AOI shown (Fig. 2b). Next the 'smoothed' image (Fig. 2C) and the computer display of outlines of identified objects are displayed. The smoothing procedure 


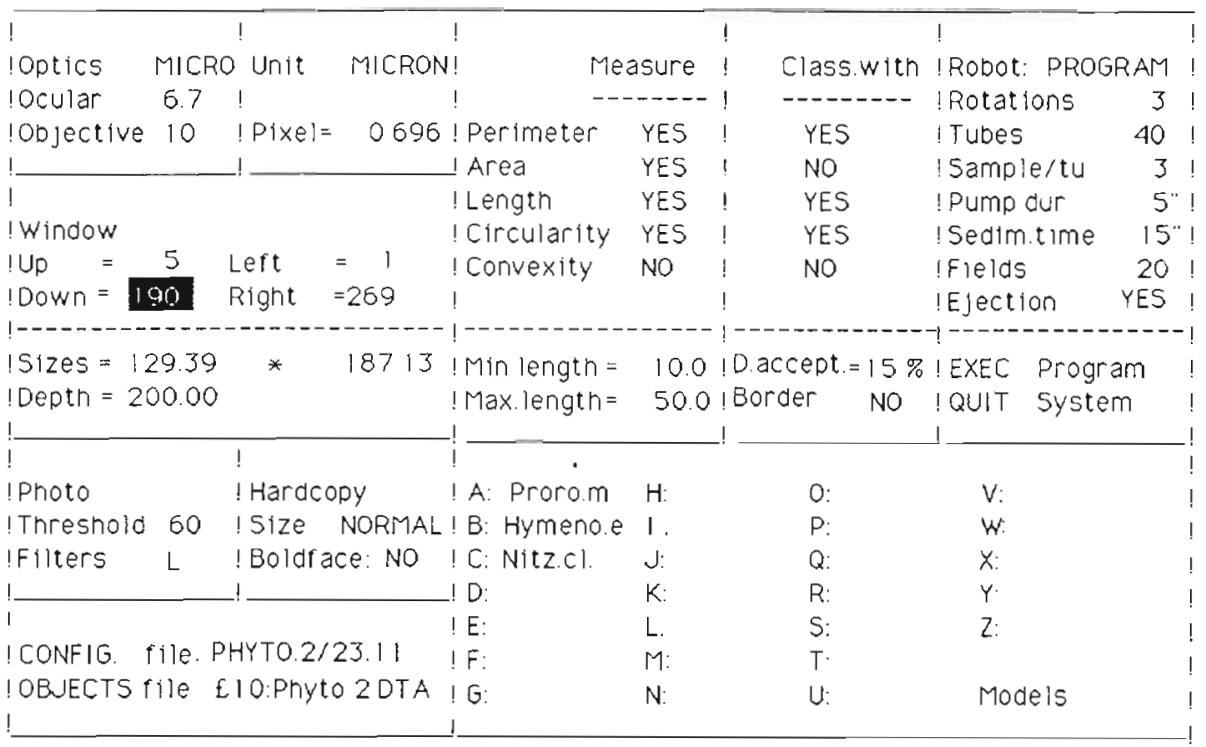

Fig. 3. Computer display of the available (interactive menu) options of the system settings. These settings determine the automatic sequence and the measurement units

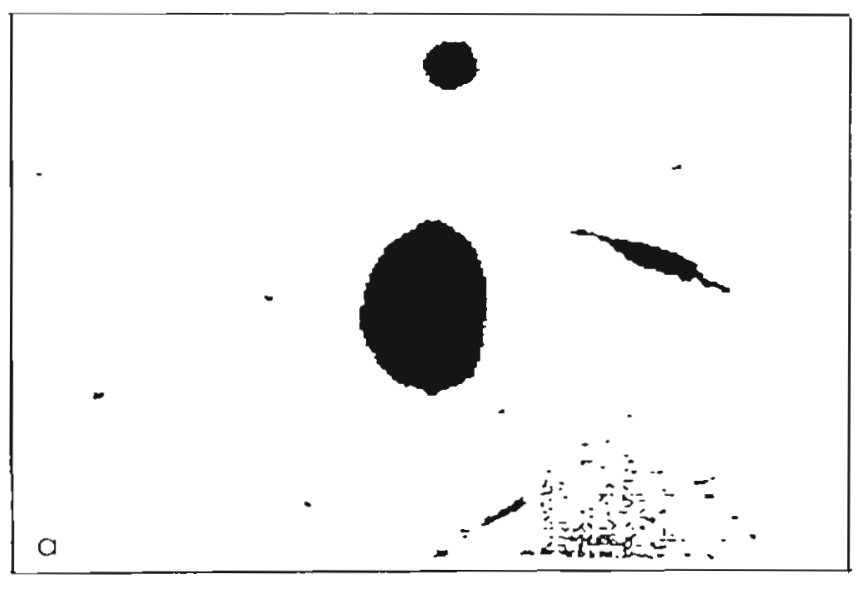

$\begin{array}{rrrrrrr}\text { C object } & \text { Perimeter } & \text { Area } & \text { Length } & \text { F.cir } & \text { F.cvx. } & \text { \% Dist./ Model } \\ 1 & 42.11 & 127.52 & 14.09 & 9038 & 10000 & 8.19 \text { Hymenoe } \\ 2 & 12181 & 996.65 & 4327 & 8442 & 10000 & 7.02 \text { Prorom. } \\ 3 & 87.57 & 144.45 & 40.31 & 23.67 & 99.34 & 7.41 \text { Nitz.cl. }\end{array}$

Fig. 4. Computer display of (a) source image, (b) outlines of accepted particles after the classification and (c) raw data print out of the accepted particles

(a non-linear filter) attributes to each pixel of the binary image the histogram median of the values of the $3 \times 3$ pixel matrix. Features extracted from each image are: perimeter, area, longest dimension, circularity and convexity factors. Use of length limits speeds up the analysis: only objects with sizes ranging between the limits will be completely analyzed. The classification of particles is done after computing the mean of the sum of the distances in percentage between the parameter of an object and the corresponding parameter of the model. The estimate of the distance from the model follows a non-quadratic 'city-block' approach (Diday et al. 1982):

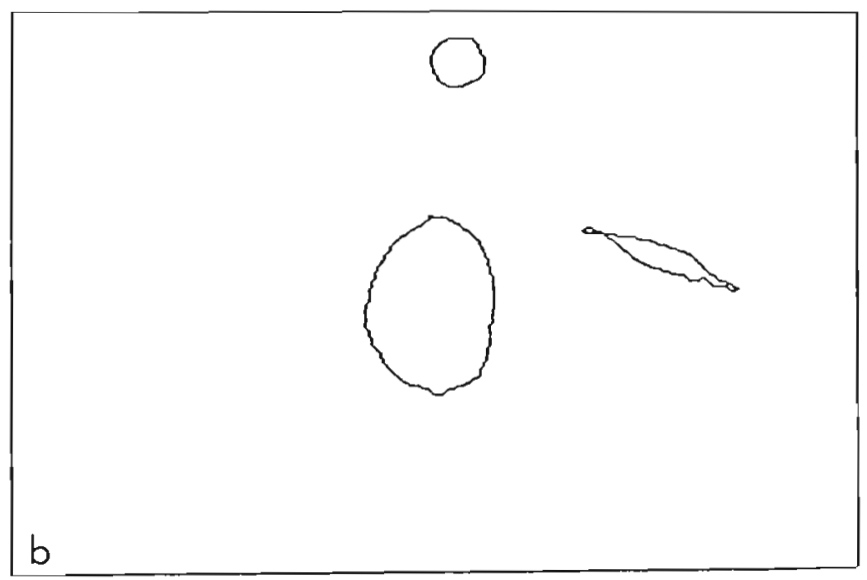

$$
\text { Dist. } \%=\frac{100}{N_{p}} \operatorname{Min}_{m=1}^{N m}\left(\sum_{p^{\prime} \in P^{\prime}}\left|\frac{O b j_{p}}{\operatorname{Mod}_{m, p}}-1\right|\right)
$$

where $N_{p}=$ number of parameters used for the classification; Min = minimum value of the expression between the parentheses computed for each model; $\mathrm{Nm}=$ number of reference models; $\mathrm{P}^{\prime} \subset \mathrm{P}, \mathrm{P}^{\prime}$ is a subset of $\mathrm{P}$ ( $\mathrm{P}$ represents the set of the 5 extracted parameters); $O \mathrm{Obj}_{\mathrm{p}}=$ parameter of the treated object; $\operatorname{Mod}_{m, p}=$ parameter $p$ of the model $\mathrm{m}$

Objects are then recognized and classified or rejected (Fig. $4 \mathrm{a}, \mathrm{b}$ ). The set-up (Fig. 3) can be saved in a file and the measurements in an object file, which can be completed any time. The results can be printed in 2 forms: (1) 


\begin{tabular}{|c|c|c|c|c|c|c|c|c|}
\hline Name & PRORO & & & MENC & & & & \\
\hline---- & ---- & - & & --- & --- & & - & \\
\hline Count & 28 equity & $20.00 \%$ & 58 e & guiv. & $41.43 \%$ & 54 & quiv & $38.57 \%$ \\
\hline Perimeter & $131.54 *-$ & $3.28 \%$ & 40.27 & + & $991 \%$ & 8659 & +- & $5: 2 \%$ \\
\hline Area & $1133.67+-$ & $502 \%$ & 106.82 & +- & $1585 \%$ & 12904 & +- & 12.50 \\
\hline Length & $45.33 \ldots$ & $256 \%$ & 13.60 & +- & $5.85 \%$ & 38.85 & +- & $4.97 \%$ \\
\hline Fac cir & $82.28 *-$ & $1.83 \%$ & 82.72 & +- & $5.71 \%$ & 2161 & +- & $823 \%$ \\
\hline Fac cru. & $9851+-$ & $0.87 \%$ & 9815 & +- & $2.60 \%$ & 97.45 & +- & $1.48 \%$ \\
\hline D1st/modl & $5.69+-$ & $3575 \%$ & 5.85 & -- & $57.84 \%$ & 676 & +- & $36 \mid 4 \%$ \\
\hline Concentr & 214674 & cell/ml & 4446 & & cell/ml & 414 & 014 & $\mathrm{cel} / \mathrm{m} \mathrm{ml}$ \\
\hline
\end{tabular}

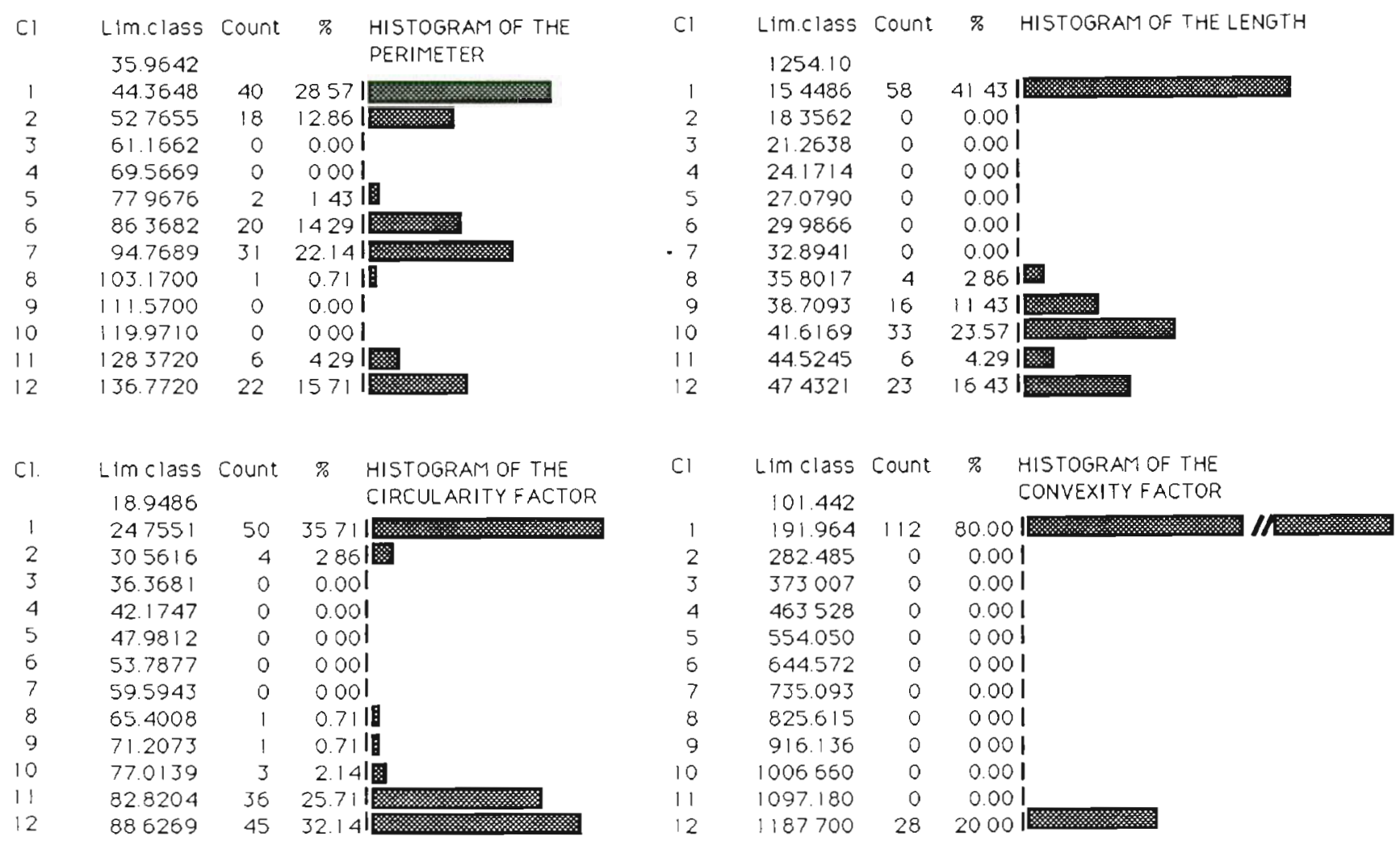

Fig. 5. Results printout of an automatic analysis of the 3 algae samples. Notice the trimodal distribution of the perimeter measurements histogram differentiating between the 3 algal species

as a table (Fig. 5) giving the mean $\pm \mathrm{SD} \%$ of the extracted parameters for each model, number of measured particles and the particle concentration per ml; (2) as a histogram of each parameter (up to 100 channels; Fig. 5) or as raw data (Fig. 4c). The results are expressed in absolute units. The image analysis procedures were written in assembly and Pascal UCSD languages. Details on the algorithms and the programming approach will be described elsewhere.

\section{RESULTS AND DISCUSSION}

Results of counting Isochrysis galbana by 3 different methods: visual, HIAC analyzer and Image Analyzer are compared in Table 2. For Runs 3 and 4, the flow speed of the sample in the HIAC particle analyzer was slower than recommended by the manufacturer. Lysing cells and cell membranes in the solution could have altered the results of counting and given artificially high results. Without Runs 3 and 4 , the replicated tests of goodness of fit (Sokal \& Rohlf 1981) of pooled results are: $G(H: E)=2.062$ and $G(H: I A)=2.371$, both significant at $p<0.1$ but not at $p<0.05$. Thus, we cannot reject the null hypothesis that number of cells counted by the 2 methods in the same volume yields a ratio of $1: 1$.

The eyepiece micrometer at 335 magnification has a resolution of $2 \mu \mathrm{m}$. Thus the variability in visual sizing 
Table 2. Comparison of 3 methods for counting a flagellate algae. Isochrysis galbana. E = eye observation, IA = Image Analyzer; $n$ $=$ number of counted algae, $G=$ replicated tests of goodness of fit (Sokal \& Rholf 1981); H:E, H:IA and E:IA = HIAC and eye counts compared to eye and Image Analyzer counts respectively. Units = count $\times 10^{4} \mathrm{ml}^{-1}$. The null hypothesis is that the number of cells counted by the 2 methods in the same volume yields a ratio of $1: 1$

\begin{tabular}{|c|c|c|c|c|c|c|c|c|}
\hline Run & HIAC & Eye & $\mathrm{n}$ & IA & $\mathrm{n}$ & $G(H: E)$ & $G(\mathrm{H}:[\mathrm{A})$ & $G(E: I A)$ \\
\hline 1 & 35.6 & 44.6 & 402 & 41.5 & 371 & $1.012 \mathrm{~ns}$ & $0.452 \mathrm{~ns}$ & $0.112 \mathrm{~ns}$ \\
\hline 2 & 58.7 & 40.4 & 1009 & 38.7 & 396 & $3.399 \mathrm{~ns}$ & $4.136^{\circ}$ & $0.037 \mathrm{~ns}$ \\
\hline 3 & 42.1 & 18.3 & 366 & 18.6 & 147 & $9.637^{\circ}$ & $9.340^{\circ}$ & $0.002 \mathrm{~ns}$ \\
\hline 4 & 33.1 & 10.4 & 625 & 10.6 & 282 & $12.452^{\circ}$ & $12.160^{\circ}$ & $0.002 \mathrm{~ns}$ \\
\hline 5 & 55.7 & 47.5 & 356 & 49.1 & 184 & $0.652 \mathrm{~ns}$ & $0.416 \mathrm{~ns}$ & $0.027 \mathrm{~ns}$ \\
\hline 6 & 3.5 & 3.9 & 291 & 4.2 & 214 & $0.196 \mathrm{~ns}$ & $0.620 \mathrm{~ns}$ & $0.119 \mathrm{~ns}$ \\
\hline 7 & 22.1 & 21.0 & 312 & 21.6 & 358 & $0.028 \mathrm{~ns}$ & $0.006 \mathrm{~ns}$ & $0.008 \mathrm{~ns}$ \\
\hline 8 & 23.1 & 20.6 & 411 & 21.1 & 435 & $0.143 \mathrm{~ns}$ & $0.091 \mathrm{~ns}$ & $0.006 \mathrm{~ns}$ \\
\hline 9 & 40.1 & 31.1 & 280 & 26.8 & 551 & $1.141 \mathrm{~ns}$ & $2.662 \mathrm{~ns}$ & $0.320 \mathrm{~ns}$ \\
\hline \multirow[t]{2}{*}{10} & 32.3 & 24.3 & 365 & 25.2 & 386 & $1.135 \mathrm{~ns}$ & $0.879 \mathrm{~ns}$ & $0.016 \mathrm{~ns}$ \\
\hline & & & & & Pooled G: & $9.768^{\circ}$ & $11.633^{\circ}$ & $1.661 \mathrm{~ns}$ \\
\hline
\end{tabular}

Table 3. Hymenomonas elongata, Nitzchia clostrium, Prorocentrum micans. Comparison of visual counting of algal solution composed of 3 algae, with results obtained by the HIAC analyzer and by the Image Analyzer. $\mathrm{C}=$ algal concentration $\times 10^{4} \mathrm{ml}^{-1}$, $N=$ number of algae analyzed, $n=$ number of replicate analyses

\begin{tabular}{|c|c|c|c|c|c|c|c|c|}
\hline \multirow[t]{2}{*}{ Run } & & \multicolumn{2}{|c|}{ Eye count } & \multicolumn{2}{|c|}{ Image analyzer } & \multicolumn{3}{|c|}{ HIAC analyzer } \\
\hline & & $c$ & $N$ & C & $\mathrm{N}$ & $\mathrm{D}$ & SD & $\mathrm{n}$ \\
\hline \multirow[t]{4}{*}{1} & H. elongata & 2.6 & 136 & 2.9 & 138 & & & \\
\hline & N. closterium & 3.1 & 166 & 2.5 & 120 & & & \\
\hline & P. micans & 0.9 & 48 & 1.0 & 46 & & & \\
\hline & Total & 6.6 & 350 & 6.4 & 302 & 7.0 & 0.4 & 3 \\
\hline \multirow[t]{4}{*}{2} & H. elongata & 3.7 & 148 & 4.5 & 139 & & & \\
\hline & N. closterium & 7.1 & 282 & 6.8 & 208 & & & \\
\hline & P. micans & 0.7 & 34 & 0.8 & 25 & & & \\
\hline & Total & 11.5 & 464 & 12.0 & 372 & 9.2 & 0.9 & 2 \\
\hline \multirow[t]{4}{*}{3} & H. elongata & 1.9 & 94 & 2.2 & 97 & & & \\
\hline & N. closterium & 3.9 & 194 & 3.2 & 140 & & & \\
\hline & P. micans & 1.6 & 84 & 1.4 & 61 & & & \\
\hline & Total & 7.4 & 372 & 6.8 & 298 & 8.5 & 0.4 & 2 \\
\hline \multirow[t]{4}{*}{4} & H. elongata & 1.2 & 112 & 1.3 & 170 & & & \\
\hline & N. closterium & 5.0 & 86 & 4.7 & 165 & & & \\
\hline & P. micans & 0.9 & 39 & 1.0 & 31 & & & \\
\hline & Total & 7.1 & 237 & 7.0 & 366 & 8.0 & 0.6 & 2 \\
\hline \multirow[t]{4}{*}{5} & H elongata & 2.9 & 123 & 2.9 & 60 & & & \\
\hline & N. closterium & 5.3 & 153 & 5.3 & 109 & & & \\
\hline & P. micans & 0.4 & 28 & 0.4 & 28 & & & \\
\hline & Total & 8.6 & 304 & 8.6 & 197 & 9.1 & 0.2 & 3 \\
\hline \multirow[t]{4}{*}{6} & H. elongata & 3.6 & 161 & 3.9 & 138 & & & \\
\hline & N. closterium & 7.4 & 144 & 6.9 & 117 & & & \\
\hline & P. micans & 0.7 & 33 & 0.7 & 25 & & & \\
\hline & Total & 11.7 & 338 & 11.6 & 280 & 10.7 & 0.7 & 2 \\
\hline \multirow[t]{4}{*}{7} & H. elongata & 1.4 & 151 & 1.1 & 146 & & & \\
\hline & N. closterium & 4.2 & 189 & 4.9 & 160 & & & \\
\hline & P. micans & 0.8 & 31 & 0.7 & 19 & & & \\
\hline & Total & 6.2 & 371 & 6.7 & 335 & 6.6 & 0.3 & 2 \\
\hline
\end{tabular}

of the small flagellate Isochrysis galbana (average diameter $5 \mathrm{um}$ ) can be as high as $20 \%$. To obtain more precise measurements, we made photographic enlargements of the algae and stage micrometer. Then 
Table 4. Isochrysis galbana, Hymenomonas elongata, Nitzchia clostrium, Prorocentrum micans. Dimensions (means + SD) of 4 algae measured visually, by the HIAC analyzer, by the Image Analyzer (IA) and by photographic enlargements, and the ratio between the photographic and experimental measurements

\begin{tabular}{|c|c|c|c|c|c|c|c|c|}
\hline Alga & Photo & $\mathrm{SD}$ & Eye & $\mathrm{SD}$ & IA & $\mathrm{SD}$ & HIAC & SD \\
\hline $\begin{array}{l}\text { 1. galbana } \\
\text { Photo/measure }\end{array}$ & 5.20 & 0.64 & $\begin{array}{l}5.37 \\
0.98\end{array}$ & 0.61 & $\begin{array}{l}5.79 \\
0.90\end{array}$ & 0.93 & $\begin{array}{l}5.24 \\
0.99\end{array}$ & 0.74 \\
\hline $\begin{array}{l}\text { H. elongata } \\
\text { Photo/measure }\end{array}$ & 13.80 & 0.86 & $\begin{array}{r}12.00 \\
1.26\end{array}$ & 0.93 & $\begin{array}{r}14.79 \\
1.02\end{array}$ & 0.24 & $\begin{array}{r}11.47 \\
1.31\end{array}$ & 0.49 \\
\hline $\begin{array}{l}N \text {. closterii } \\
\text { Photo/measure }\end{array}$ & 42.53 & 0.63 & $\begin{array}{r}42.72 \\
1.01\end{array}$ & 1.40 & $\begin{array}{r}39.07 \\
1.09\end{array}$ & 1.38 & $\begin{array}{l}8.56 \\
4.97\end{array}$ & 0.19 \\
\hline $\begin{array}{l}\text { P. micans } \\
\text { Photo/measure }\end{array}$ & 43.07 & 2.17 & $\begin{array}{r}40.63 \\
1.06\end{array}$ & 1.32 & $\begin{array}{r}39.35 \\
1.09\end{array}$ & 0.98 & $\begin{array}{r}19.67 \\
2.19\end{array}$ & 0.91 \\
\hline
\end{tabular}

we compared the measurements of the diameter of $l$. galbana by the 3 methods to the measurements done on the enlargements (Table 2).

Isochrysis galbana is a small spherical haptophyte. Our measurements (Table 3 ) do not differ significantly from one another. The results from the HIAC analyzer depend on assumptions made in extrapolating the size of particles. Harbison \& McAllister (1980) calculated equivalent spherical diameter (ESD) from average cell volume obtained from a Coulter Counter after summing the volumes for each channel that contained $>10 \%$ of the total volume. When our sample was perfectly clean (without broken or empty cells, bacterial or ciliate contamination) results approximated the expected ones; in the presence of debris (Runs 3 and 4 ; Table 2 ) results were less statisfactory

Differences between the 3 methods in counting are not significant at $p<0.05$, but results obtained by the HIAC in comparison to the Image Analyzer and visual counting are significant at $p<0.1$. The concentration of cultured algae was too high for the HIAC analyzer. It was therefore necessary to dilute the original solution (most frequently $100 \times$ ), an additional step which probably increased the error in counting.

The algae Hymenomonas elongata, Nitzchia closterium and Prorocentrum micans are commonly used as diet in zooplankton culture or feeding experiments. In our experimental design we counted, differentiated and measured 7 solutions composed of identical sample volumes $(30 \mathrm{ml}$ ) of each of the 3 algal species (Table 3 ). The algal concentrations of these solutions were unknown prior to the experiment.

The sensor analyzers are not adapted to classify particles morphometrically. The histogram of the results obtained by the HIAC analyzer (Fig. 6) shows a characteristic situation. (1) No difference between the algae Hymenomonas elongata and Nitzchia closterium: their ESDs are identical in spite of the difference in their length and form. (2) The ESD of the spherical $H$. elon- gata approximated the visual sizing. (3) The ESD of Prorocentrum micans was given as $25 \mu \mathrm{m}$ instead of 43 um (mean length measured on photographic enlargements) and the ESD of $N$. closterium as $11 \mu \mathrm{m}$ instead of the mean length of $42.5 \mu \mathrm{m}$ (Table 4 ). The ratio of photographic enlargement measurements to experimental measurements shows the good approximation of the sizes obtained by the image analyzer and by eye, but the high ratio obtained for the non-spherical algae by the HIAC shows that this particle counter cannot correctly measure the linear dimensions of these algae (Table 4). The combination of 5 parameters allows a better differentiation between particles as shown by the perimeter histogram (Fig. 5) when compared to a simple parameter measured by the HIAC analyzer (Fig. 6).

Automatic analyses of 20 fields with a density of 7 objects per field required $186 \mathrm{~s}$. Included in this time are: the automatic sampler sequence including mixing; sample transfer to the flow chamber; $(10$ s) sedimenta-

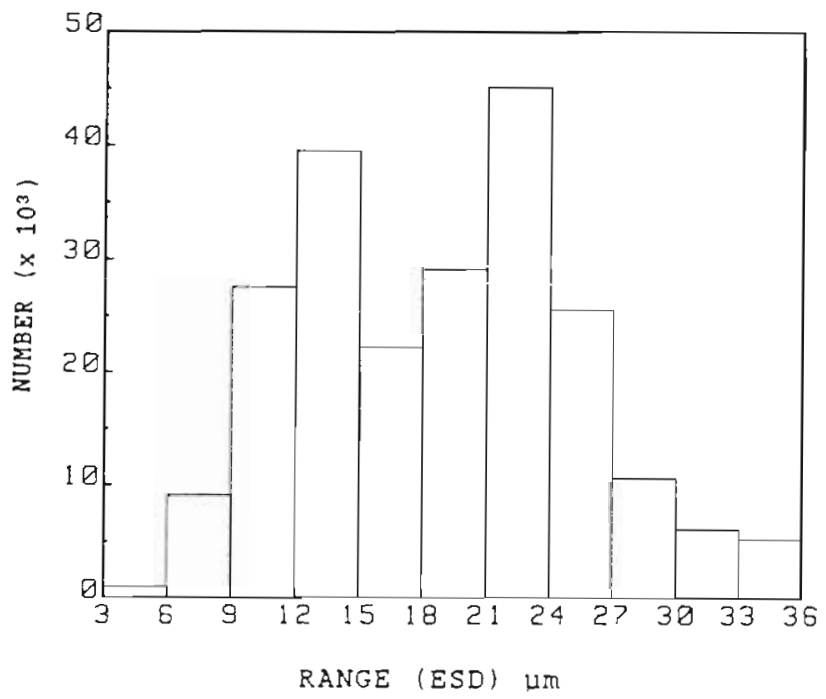

Fig. 6. Bimodal appearance of the 3 algal size spectrum analyzed by the HIAC particle analyzer 
tion interval; ejection of the sampled tube; image acquisition, smoothing, analysis and automatic displacement of the microscope stage; classification of objects and printout of results. With 2 objects per field the time was $170 \mathrm{~s}$, and with ca 120 objects per field, 20 fields were treated in 16 min, which gives a speed of 4.6 objects $s^{-1}$.

When more objects are present in the field, the relative speed of the treatment is greater, but debris in the sample increases the analysis time, since the parameters of every object are extracted. In addition, with fewer models, the speed of the treatment is increased.

There are several limitations to the use of the image analyzer presented in this paper. The image to be analyzed requires sharp outlines for good recognition. Aggregated or superimposed particles are rejected. For good estimations of parameters, particles require a surface of at least 100 pixels. In contrast, image analysis has the following positive features: easy interaction with the operator, inexpensive equipment, high speed of treatment compared to existing systems, and adaptability of the method to situations other than algal cultures (see below).

The Image Analyzer presented in this paper can be used also as a manual sizer. By an arrow the operator can access any object on the screen and store the extracted parameters. The image-improvement routines can be used for individual particles at any point and a table of results (parameter values per object) can be printed as well as the corresponding histograms.

A modified method was used for the counting, measurement and identification of organisms larger than $200 \mu \mathrm{m}$. Samples were successively filtered on plankton nets with different porosity. Each size class of the sample was treated separately. The sample was filled into a custom designed $30 \mathrm{~cm}$ long, $2 \mathrm{~cm}$ wide chamber. The depth varied from 0.4 to $2 \mathrm{~cm}$. After sedimentation, silhouette photographs (Edgerton et al. 1984, Braconnot 1985) were taken. The preparation of the photographs takes longer than the direct transfer of organisms, but the error due to the sampling of a fixed population (it is difficult to maintain a preserved zooplankton sample evenly distributed in a jar when using a flow chamber) is small. Another advantage is the possibility of manipulating non-preserved samples. Living organisms adopt characteristic positions and their identification is easier. The short duration of the flash freezes their movement. The depth of the chamber is only slightly larger than the smallest dimension of the size class examined. A computer monitored motorized stage (on X and $Y$ axes) allows automatic handling of 250 exposure drums of $24 \times 36$ negative films. Our preliminary size analysis of a zooplankton population yielded the following results: manual sizing of 110 copepods required ca $20 \mathrm{~min}$. The automatic analysis lasts ca $8 \mathrm{~min}$. In $4.3 \mathrm{~s}$ copepod $^{-1}$ we can obtain its longest dimension, area, perimeter and the 2 form factors, as well, as the frequency histograms for the sampled population. The results concerning the automatic treatment of zooplankton samples will be discussed elsewhere.

It should be mentioned that the described system is not designed for taxonomic differentiation, but only for routine counting and classification of particles of simple forms in an aqueous suspension.

Acknowledgements. This study was carried out with support from Ysebaert SA. We are grateful to S. Tanguy, P. Chang, I Palazzoli, N. Pontet and C. Verdan for technical assistance and N. Holland, L. Holland, P. Nival, R. Fenaux and S. Dallot for critical reviews which improved the manuscript.

\section{LITERATURE CITED}

Asano, K., Tanaka, S. (1984). Measurement of fish eggs with an image processor. Bull. Fac. Fish. Mie Univ. 11: 135-140

Bjørnsen, P. K. (1986). Automatic determination of bacterioplankton biomass by image analysis. Appl. environ. Microbiol. 51: 1199-1204

Braconnot, J.-C. (1985). Confection et utilisation de photogrammes pour études de croissance, de développement et d'abondance de populations d'espèces pélagiques marines gélatineuses. C. $\mathrm{r}$ hebd. Seanc. Acad. Sci., Paris 3: 563-566

Chapeau, Ch., Gagnon, C. (1987). Nitrocellulase and polyvinyl coatings prevent sperm adhesion to glass without affecting the motility of intact and demembranated human spermatozoa. J. Androl. 8: 34-40

Chehdi, K., Boucher, J. (1986). Extraction automatique de paramètres descriptifs par l'analyse d'images. Application à la biologie marine (zooplancton). Innov. Tech. Biol. Med. 7: $386-399$

Dietrich, A., Uhlig, G. (1984). Stage specific classification of copepods with automatic image analysis. Crustaceana 3 : $159-165$

Diday, E., Lemaire, J., Pouget, J., Testu, F. (1982). Eléments d'analyse de données. Dunod, Paris

Edgerton, H. E., Moffit, H. A., Youngbluth, M. J. (1984). Highspeed silhomette photography of live zooplankton. In: Smith, P. F. (ed.) Underwater photography, scientific and engineering application. Van Nostrand Reinhold, New York, p. 305-319

Estep, K. W., MacIntyre, F., Hjörleifsson, E., Sieburth, J. McN. (1986). MacImage: a user-friendly image-analysis system for the accurate mensuration of marine organisms. Mar. Ecol. Prog. Ser 33: 243-253

Ferson, S., Rohlf, F. J., Koehn, R. K. (1985). Measuring shape variation of two-dimensional outlines. Syst. Zool. 34: 59-68

Furuya, K. (1982). Measurement of phytoplankton standing stock using an image analyzer system. Bull. Plankton Soc. Japan 29: 133-135

Guillard, R. R. L. (1975). Culture of phytoplankton for feeding marine invertebrates. In: Smith, W. L., Chanley, M. M. (eds.) Culture of marine invertebrates. Plenum Publishing Co., New York, p. 29-60

Harbison, G. R., McAllister, V L. (1980). Fact and artifact in copepod feeding experiments. Limnol. Oceanogr. 25: 971-981

Jeffries, H. P., Berman, M. S., Poularikas, A. D., Katsinis, C., 
Melas, 1., Sherman, K., Bivins, L. \{1984\}. Automated sizing, counting and identification of zooplankton by pattern recognition. Mar Biol. 78: 329-334

Jeffries, H. P., Sherman, K., Maurer, R., Katsinis, C. (1980). Computer processing of zooplankton samples. In: Kennedy, V. (ed.) Estuarine perspectives. Academic Press, New York, p. 303-316

Pough, P. R. (1976). The application of particle counting to an understanding of the small-scale distribution of plankton. In: Steele, J. H. (ed.) Spatial pattern in plankton communities. Plenum Press, New York, p. 111-129

Rolke, M., Lenz, J. (1984). Size structure analysis of zooplankton samples by means of an automated image analyzing system. J. Plankton Res. 6: 637-645

This article was submitted to the editor
Sheldon, R. W., Parsons, T. R. (1976). A practical manual on the use of the Coulter Counter in marine science. Coulter Electronics, Toronto

Sieracki, M. E., Johnson, P. W., Sieburth, J. MCN. (1985) Detection, enumeration, and sizing of planktonic bacteria by image-analyzed epifluorescence microscopy. Appl. environ. Microbiol. 49: 799-810

Sokal, R. R., Rohlf, F. J. (1981). Biometry. The principles and practice of statistics in biological research, 2nd edn. Freeman, San Francisco

Tsuji, T., Nishikawa, T. (1984). Automated identification of red tide phytoplankton Prorocentrum triestinum in coastal areas by image analysis. J. oceanogr Soc. Japan 40: $425-431$

Manuscript first received: October 23, 1987

Revised version accepted: August 2, 1989 